\title{
Relations between Agreeableness and perceived support in family relationships: Why nice people are not always supportive
}

\author{
Susan J. T. Branje \\ Utrecht University, \\ The Netherlands
}

\author{
Cornelis F. M. van Lieshout \\ Radboud University Nijmegen, \\ The Netherlands
}

\author{
Marcel A. G. van Aken \\ Utrecht University, \\ The Netherlands
}

\begin{abstract}
Do more agreeable individuals perceive more support, and are they perceived as more supportive, across all family relationships or only within specific relationships? In a study of 256 Dutch twoparent families with two adolescents, we examine whether links between Agreeableness and support are generalised across relationships or occur within specific relationships. Social Relations Model analyses showed that individuals who perceive their family members as more agreeable perceive more support from family members across relationships. Also, individuals who are perceived as more agreeable are perceived as more supportive across relationships, except for mothers. In addition, individuals who perceive specific family members as more agreeable perceive these specific members as more supportive. However, individuals who are perceived as more agreeable perceive more support only within specific relationships. Thus, agreeable family members are supportive across relationships, but agreeable family members perceive support only within specific relationships.
\end{abstract}

\section{Introduction}

Individual differences in perceived support can be explained intrapersonally by characteristics of the perceiver, but also interpersonally by characteristics of the person providing the support (e.g., Lakey \& Cassady, 1990; I. G. Sarason, Pierce, \& Sarason, 1990). Such a characteristic is the Big Five factor Agreeableness: Individuals who are highly agreeable are motivated to maintain positive relationships with others (Jensen-Campbell \& Graziano, 2001), and they tend to perceive more support from family members and are perceived as more supportive by family members (Branje, Van Lieshout, \& Van Aken, 2004). However, agreeable individuals do not have to be supportive toward everyone, and not everyone will support them. These links between support and Agreeableness may occur across relationships and within relationships. The link occurs across relationships when an individual perceives all family members as agreeable and supportive or when an individual is perceived as agreeable and supportive by all family members. Similarly, when an individual perceives all family members as agreeable and is perceived as supportive by all family members, or when an individual perceives all family members as supportive and is perceived as agreeable by all family members, the relation is also across relationships. In contrast, the link occurs within specific relationships when an individual perceives a specific family member as agreeable and supportive, or when an individual perceives a specific family member as agreeable and this specific family member perceives the individual as supportive. Using a Social Relations Model, the present study investigated the extent to which the links between Agreeableness and support in families with two parents and two adolescent children occur across relationships and the extent to which they occur within specific relationships.

\section{The Social Relations Model and Agreeableness and support in the family context}

The Social Relations Model (SRM; e.g., Cook, 1994; Kenny, 1994; Kenny \& La Voie, 1984) is a statistical model that enables to distinguish interdependent or shared dyadic perspectives and behaviours from those that are independent and unique to each participant. The SRM enables involving the perceptions of all members of the family in the study while controlling for the statistical interdependence of the collected data of different members of the same family. Specifically, it allows to identify that part of variance in social behaviour (such as perceived support) that is due (1) to a family member's disposition to perceive support from all other family members, the actor effect, (2) to a particular family member's tendency of being perceived as supportive by all other family members, the partner effect, (3) to the relationship effect, or the unique relationship between two family members that makes a family member perceive support from one specific partner, but not from others, and (4) to the family effect, or the mean level of support perceived by all of the family members. Thus, the SRM makes a sharp distinction between the effects of dispositional characteristics of individuals, the dyadic relationships between individuals, and the family to which those individuals belong. SRM analyses have revealed that both perceived support and Agreeableness in family relationships are a function of characteristics of each partner in a relationship 
as well as the unique relationship between the partners (Branje, Van Aken, \& Van Lieshout, 2002; Branje, Van Aken, Van Lieshout, \& Mathijssen, 2003). High actor variance showed that differences in perceived support and Agreeableness of individual family members are to a large extent due to actor effects, or individual family members' disposition to generally perceive support and Agreeableness from other family members. Perceivers tend to differ in the extent to which they elicit support from others, and in their stable beliefs about the supportiveness of others in general (Baldwin, 1992; Lakey \& Cohen, 2000; Pierce, Baldwin, \& Lydon, 1997; B. R. Sarason, Pierce, \& Sarason, 1990; I. G. Sarason, Sarason, \& Shearin, 1986). The extent to which two family members perceive support from each other or are agreeable to each other was also found to be partly relationship-specific, depending on the unique relationship between them. Perceptions of support are thought to be affected by the specific supportive actions of the partner: Some individuals are more likely to help and support someone than others (Lakey, McCabe, Fisicaro, \& Drew, 1996a; Lakey, Adams, Neely, Rhodes, Lutz, \& Sielky, 2002). Differences in perceived support or Agreeableness did not seem to depend much on individual family member's partner effects, or dispositions to be perceived as supportive or agreeable by others. More likely, the effects of perceiver and partner are likely to interact, resulting in support perceptions that are in part relationship-specific (Branje et al., 2002). In the present paper we will extend these studies by examining the links between the SRM components of perceived support and Agreeableness in families with adolescent children.

\section{Links between perceived support and Agreeableness in the family context}

Agreeableness is related to perceived support in close relationships (Asendorpf \& Van Aken, 2003; Lakey et al., 2002). In families with adolescents, Agreeableness appeared as the Big Five personality factor most strongly related to perceived relational support (Branje et al., 2004). In fact, perceived support was linked to the Agreeableness of the perceiver as well as to the Agreeableness of the provider of support: Individuals who are more agreeable perceive more support from their family members and are perceived as more supportive by their family members. These findings may not be surprising because Agreeableness is related to motives for maintaining positive relationships with important others (Jensen-Campbell \& Graziano, 2001). More agreeable individuals are likely to interpret and react more positively upon behaviours of others, and thereby facilitate social behaviours such as intimacy (Finch \& Graziano, 2001). Thus, the Agreeableness of individuals may help them to maintain supportive relationships with family members.

Given this evidence, understanding how exactly perceived support and Agreeableness in the family context are related to each other becomes important. The relation between Agreeableness and perceived support may be due to individual characteristics of family members that generalise across relationships, but may also involve processes within specific relationships. That is, individuals may in part be agreeable in general, toward all their relationship partners, and therefore perceive all these relationship partners as agreeable or be perceived as agreeable by all these partners. Additionally, individuals may be differentially agreeable towards specific relationship partners, and this relationship-specific Agreeableness may be related to the support uniquely perceived from or by this specific partner. In a sample of college students, relationship processes were found to play a role in the link between personal characteristics and support perceptions: Depending on their own traits, perceivers differ in how they combine information about target traits to judge the supportiveness of the target (Lutz \& Lakey, 2001). This finding is consistent with theories on social relationships emphasising bidirectional, reciprocal processes in which dyadic partners mutually influence each other (Lollis \& Kuczynski, 1997). Hence, the specific match between relationship partners seems important for support judgments and the link between Agreeableness and perceived support may also be in part relationship-specific. In dyadic relationships of families with adolescent children, we will examine to what extent links between Agreeableness and perceived support are generalised across relationship partners and to what extent they are relationship-specific.

The SRM allows us to assess links between family members' Agreeableness and perceived support across relationships and within relationships (see also Finkenauer, Engels, Branje, \& Meeus, 2004). Additionally, the SRM allows us to consider these relations intrapersonally (i.e., are more agreeable family members more supportive themselves?) and interpersonally (i.e., do more agreeable family members get more support from others?). Correlated actor and partner effects of support and Agreeableness would indicate links across relationships. Intrapersonal relations across relationships would exist when individuals who perceive support from all family members perceive all family members as agreeable (correlated actor effects within a person), and also when a particular family member who is perceived as supportive by all others is perceived as agreeable by all others (correlated partner effects within a person). Interpersonal relations across relationships would be demonstrated if an individual who perceives all family members as supportive is perceived as agreeable by all family members, or when an individual who perceives all family members as agreeable is perceived as supportive by all family members (actor effect-partner effect correlations of two persons).

Links within specific relationships would emerge when the relationship effects of perceived support and Agreeableness are correlated. Evidence for intrapersonal links within relationships would occur when a family member who perceives a specific relationship partner as supportive also perceives that specific relationship partner as agreeable (correlated relationship effects within a person). Interpersonal links within relationships would be evident when a family member who perceives a specific relationship partner as supportive is perceived as agreeable by that specific relationship partner (correlated relationship effects between two persons).

Hence, we will examine whether Agreeableness and perceived support in adolescents' families are related across relationships or within relationships. Based on the findings of high actor effects on both perceived support and Agreeableness, we hypothesise that intrapersonal links occur mainly across relationships, due to the characteristics of the perceiver. That is, family members who perceive more support across relationships are expected to perceive others as more agreeable across relationships. Interpersonally, relationship-specific links between Agreeableness and support are expected to be stronger than links across relationships. Family members will influence each other reciprocally mainly by their unique 
perceptions of each other, or their specific dyadic match, and not so much by their general perceptions.

\section{Method}

\section{Participants}

Participants were recruited for the Family \& Personality study, a longitudinal study of 285 Dutch two-parent families with two adolescents (Haselager \& Van Aken, 1999). A representative selection of 23 municipalities in the Netherlands provided lists of families with two adolescents between the ages of 11 and 15 years. After a mailing to the families announcing the study, interviewers contacted the families by phone and invited them to participate. A total of $50 \%$ of the families contacted agreed to take part in the study. Only those families were included in the study in which all four members were willing to participate. Frequently given reasons for not wanting to participate were that the family had no interest in the topic of the project, or that a specific family member did not want to collaborate. Thus for all participating families, two parents and two adolescents participated in the study. Because we employed a four-person family design in the SRM analyses (Kashy \& Kenny, 1990), the two adolescents participating in the study will be distinguished as the "older" and the "younger" adolescent throughout the manuscript.

The average age was 43.9 years $(S D=3.27)$ for the fathers and 41.7 years $(S D=3.71)$ for the mothers. The older adolescents (142 boys, 143 girls) were on average 14.5 years $(S D=0.83)$, and the younger adolescents (135 boys, 150 girls) were on average 12.3 years $(S D=0.76)$. Almost all respondents were of Dutch origin. Only in $4 \%$ of the families did parents report that they were not born in the Netherlands. A small proportion of the parents, $17 \%$ of the mothers and $19 \%$ of the fathers, had finished only primary or low secondary education. Forty-six per cent of the fathers and $28 \%$ of the mothers had finished college or university education. All adolescents lived with their natural mother and father at their parental home. Concerning birth order, in 224 families (79\%) the older adolescent who participated in the study was actually the oldest child in the nuclear family. Furthermore, in 219 families $(77 \%)$ the younger adolescent had only one older sibling.

\section{Procedure}

Families were followed over a period of 3 years, with yearly measurement waves. In each measurement wave, trained interviewers visited the families at home and asked the mother, the father, and each of the two target adolescents to fill out a battery of questionnaires. All four family members completed questionnaires assessing the extent to which they perceive support from the three other family members and the extent to which they perceive themselves and their family members to be agreeable. The presence of the interviewer encouraged complete responding and prevented discussions regarding individual items or the topics in the questionnaires among the family members during completion of the questionnaires. Both adolescents in the family were given a CD gift certificate after completion of the questionnaires. Furthermore, 10 families who filled out all questionnaires could gain a travel voucher (value of about $€ 900$ ) as a reward.

\section{Measures}

Family members received a large battery of questionnaires. Only those questionnaires relevant to the questions addressed in the present study will be discussed here. All measures were adapted so as to generalise to and be appropriate in all types of relationships in the family. Relationship specificity was achieved by formulating items as statements and instructing participants to imagine each specific family member (i.e., father, mother, sibling) before rating each statement for the specific partner.

Perceived support. Perceived relational support was measured with the Relational Support Inventory (RSI; Scholte, Van Lieshout, \& Van Aken, 2001). The inventory involves 24 items measured along a 5-point Likert scale ranging from very untrue of this person (1) to sometimes untrue, sometimes true of this person (3) to very true of this person (5).

The questionnaire includes questions on the quality of information provided (e.g., "This person explains or shows how I can make or do something"), the respect for autonomy of the relationship partner (e.g., "This person lets me solve problems as much as possible on my own but also provides help when I ask for it"), the emotional support provided (e.g., "In this person's view, I can't do anything right: he/she is always criticising me"), and the convergence of goals (e.g., "This person and I have many conflicts with regard to school achievement, the future, or career opportunities"). An overall support score for each of the 12 family relationships was computed by averaging the scores on the 24 items within each measurement wave (i.e., considering that support perceptions are directional, father $\rightarrow$ mother and mother $\rightarrow$ father are two relational perceptions). Reliabilities of these support scores were on average $\alpha=.82$ with a range of $\alpha=.80$ to $\alpha=.87$.

Agreeableness. A Dutch adaptation (Gerris, Houtmans, Kwaaitaal-Roosen, Schipper, Vermulst, \& Janssens, 1998) of adjective Big Five personality markers selected from Goldberg (1992) was used to have family members judge their own Agreeableness and the Agreeableness of the other three participating family members. The Big Five factor Agreeableness was measured using six items: pleasant, helpful, friendly, obliging, agreeable, and sympathetic/nice. The participants rated the adjectives along a 7-point Likert scale ranging from (1) very untrue of this person to (4) sometimes untrue, sometimes true of this person to (7) very true of this person. The internal consistencies (Cronbach's alpha) ranged from .84 to .86 for judgments by fathers, from .82 to .88 for judgments by mothers, from .80 to .90 for judgments by older adolescents, and from .76 to .87 for judgments by younger adolescents.

\section{Analyses}

We used a SRM analysis to estimate the links across relationships and within relationships between Agreeableness and perceived support. A minimum sample size of 50 families is required to have enough power for an SRM analysis (Kashy \& Kenny, 1990), so our sample size is large enough. A SRM analysis was performed on the covariance matrix of each family member's perceived support from the three other family members (i.e., $4 \times 3=12$ family relationships) and each 
family member's Agreeableness as judged by all family members (i.e., $4 \times 4=16$ judgments of Agreeableness). We did not estimate separate models for perceived support and Agreeableness but instead estimated both concepts in a single model. The SRM analysis explores the extent to which variance in perceived support and Agreeableness in each of the 12 family relationships is due to actor, partner, relationship, and family effects. All these effects are estimated independently, controlling for all remaining effects. That is, a relationship effect is estimated after controlling for actor, partner, and family effects.

For the four-person family design, there are 12 relationship variances, 1 for each dyadic perception. There are 12 unidirectional indicators of perceived support and 16 indicators of Agreeableness. However, to reliably estimate the 12 relationship effects (that is, without random error variances), at least 24 indicators are needed for each construct. In order to obtain enough indicators, replications of each of the observed variables can be used. Therefore, we used judgments of perceived support and Agreeableness from the first and second measurement wave as separate indicators of perceived support and Agreeableness, which produced (12 relationships $\times 2$ scales $=) 24$ observed scores of perceived support and (16 judgments $\times 2$ scales $=$ ) 32 scores of Agreeableness (see Cook, 1993, 1994, 2000).

Thus, a SRM analysis was conducted with each of the two perceived support and Agreeableness scales (the indicators) included to partition the variance in perceived support and
Agreeableness into actor, partner, relationship, and family effects for perceived support and Agreeableness, respectively. The actor, partner, relationship, and family effects technically constitute separate factors or latent variables within a confirmatory factor analysis (see Figure 1; Cook, 1994). The factor loadings (i.e., paths from the latent variables to the indicators) were all fixed at 1.0 to be able to identify the SRM factor variances (Kashy \& Kenny, 1990). We allowed for correlations among measurement errors for each indicator per rating family member (e.g., for each indicator of father's perceived support, we allowed father's measurement errors for their perceived support from mother, older adolescent, and younger adolescent to correlate). The different variances for perceived support and Agreeableness were simultaneously estimated using structural equation modelling with maximum likelihood estimation procedures (LISREL 8.30; Jöreskog \& Sörbom, 1996). Missing cases were deleted listwise, which reduced the sample to 256 families.

In the same SRM analysis, we also estimated the hypothesised relations between the SRM components of perceived support and Agreeableness as specified in Figure 2. The model showed an acceptable fit with our data set given the complexity of the model and the number of variables involved. The $\chi^{2}$ of this model was $2041.54, p<.01, d f=1381$, the NonNormed Fit Index (NNFI) was .94, and the Root Mean Square Error of Approximation (RMSEA) was .04, indicating an acceptable fit of the overall model (Browne \& Cudeck, 1989).

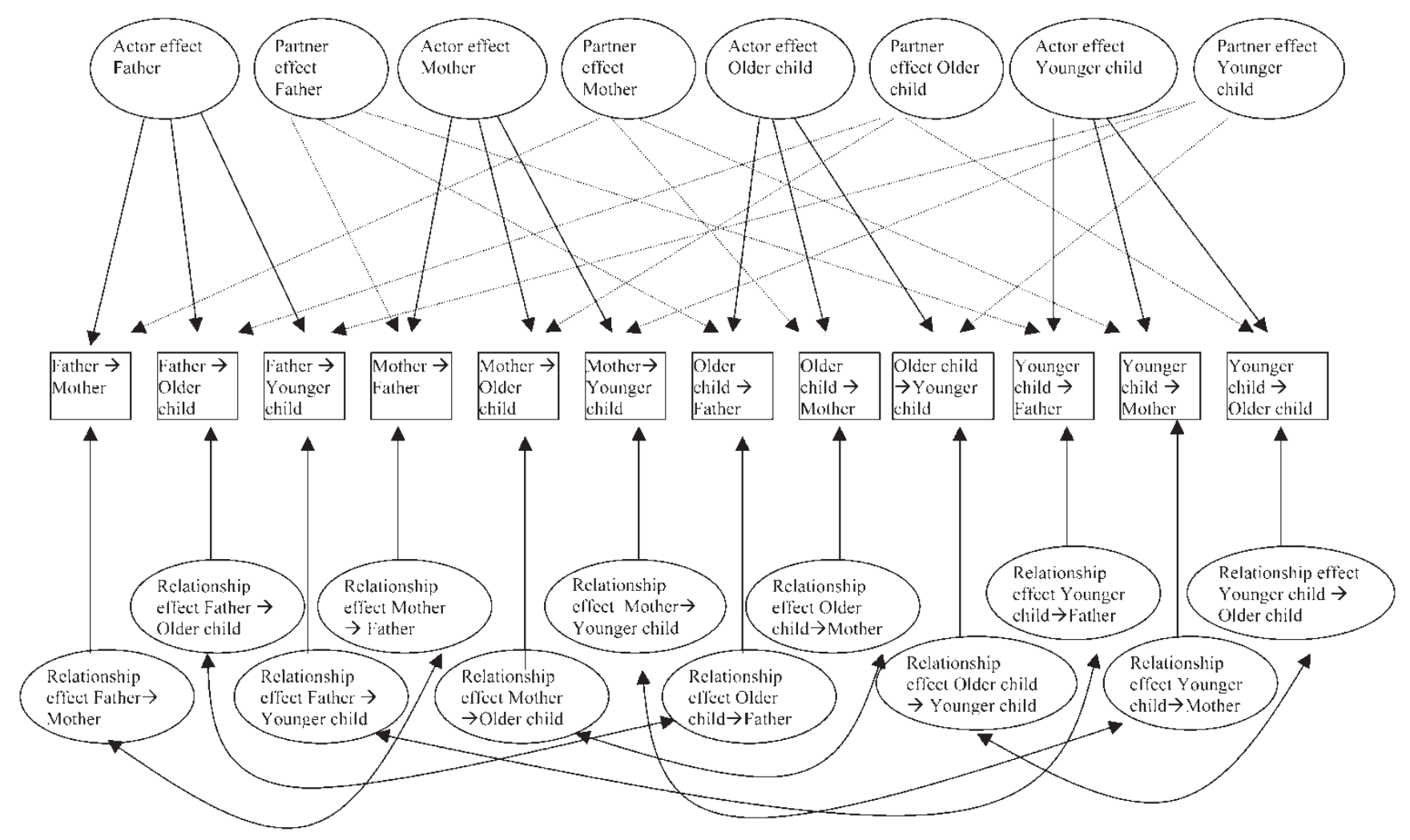

Figure 1. Parameters of the LISREL model. Rectangles represent the observed measures; ellipses represent the latent SRM components of support or Agreeableness. One-headed arrows indicate factor loadings. All loadings are fixed at 1. Double-headed arrows represent dyadic reciprocity correlations. All of the observed variables loaded on the latent SRM component "family effect", which is not included in the figure. For Agreeableness, self-reports were also included that were allowed to load on the actor effect and partner effect of the reporting person. Figure 1 displays the parameters for one indicator of perceived support or Agreeableness only; the other indicator loads on the same latent factors in a similar manner. 


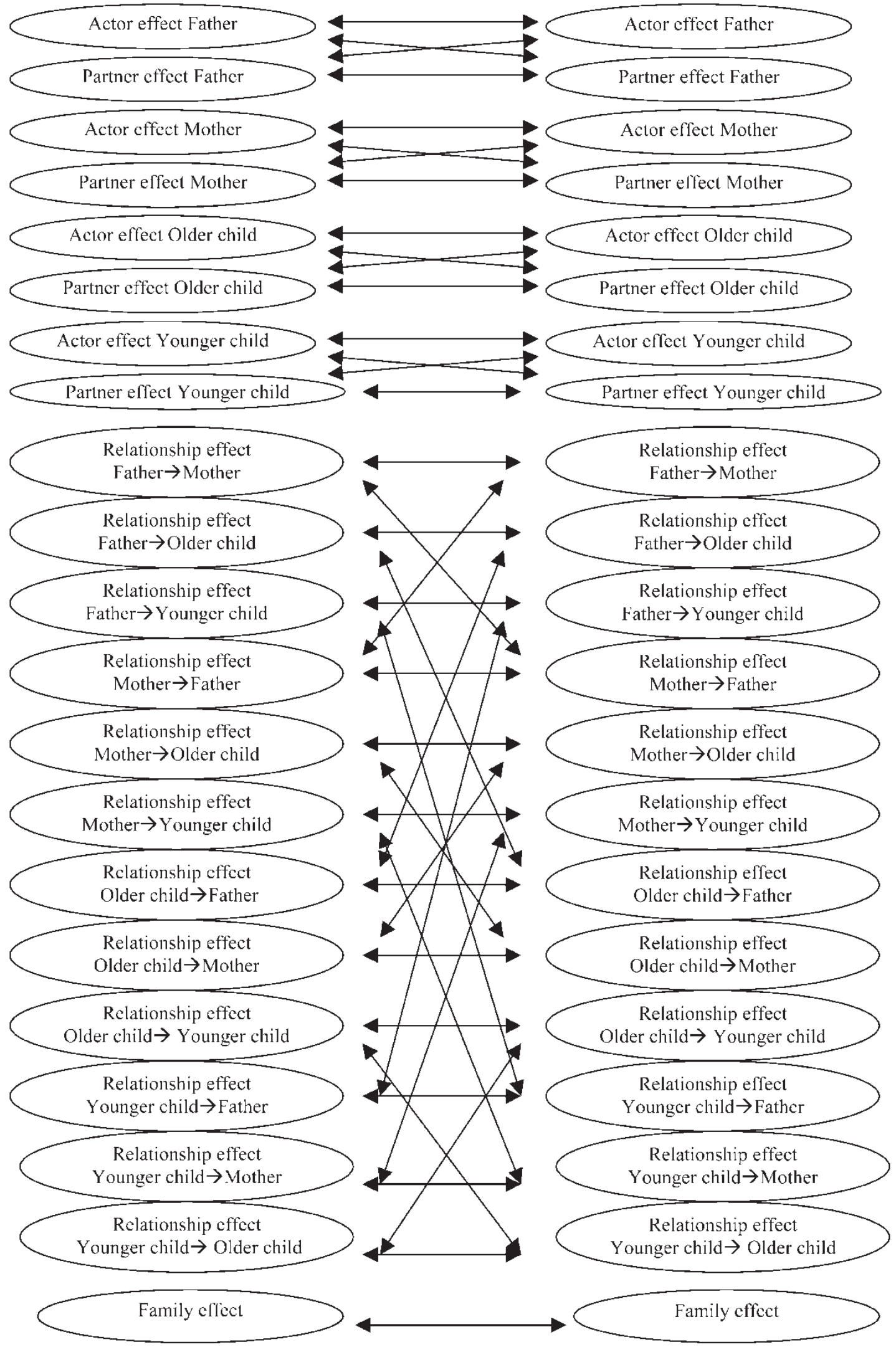

Figure 2. SRM correlations between Agreeableness and support. 


\section{Results}

The simple main SRM effects (actor, partner, relationship, and family effects) for perceived support and for Agreeableness separately will not be described in the present study because they have been addressed in earlier studies (Branje et al., 2002, 2003). We will focus on the relations between different SRM effects of Agreeableness and perceived support, to address our hypotheses regarding the links between perceived support and Agreeableness across and within family relationships.

\section{Links between perceived support and Agreeableness across family relationships}

We first examined our hypotheses regarding links between Agreeableness and perceived support across family relationships. To examine whether more agreeable family members are more supportive, the correlations between a family member's actor effect for perceived support and that family member's actor effect for Agreeableness were computed, as well as the family member's partner effect for perceived support and that family member's partner effect for Agreeableness (Table 1). The significant correlations of actor effects indicate that individuals who perceive more support from all their family members perceive all their family members as more agreeable. In addition, the correlations of partner effects reveal that individuals who are perceived as more agreeable by all their family members are perceived as more supportive by all their family members as well, except for mothers. This suggests that mothers are supportive regardless of their Agreeableness. Mothers' partner effect of support was the only SRM effect that was not significant, which may be related to this finding.

To examine whether family members who are more agreeable perceive more support, the correlations between a family member's actor effect for perceived support and that family member's partner effect for Agreeableness were computed, as well as the family member's partner effect for perceived support and that family member's actor effect for Agreeableness (Table 1). The nonsignificant correlations indicate that individuals who perceive more support from all family members are not perceived as more agreeable by all family members. Also, family members who are perceived as more supportive by all family members do not perceive more Agreeableness from all family members.

\section{Links between perceived support and Agreeableness within family relationships}

Next, we examined the links between Agreeableness and perceived support within family relationships. To examine whether family members who are more agreeable within specific relationships are also more supportive in these relationships, the correlations between a family member's relationship effect for perceived support and that family member's relationship effect for Agreeableness were computed (Table 2). All correlations were significant except for the relationship of the younger child towards the mother, which indicates that individuals who perceive a specific family member as more agreeable perceive more support from this specific partner than individuals who perceive that family member as less agreeable. The strength of the correlation coefficients differed across relationships, however. $z$-score comparisons of correlations per family member showed that in the horizontal marital and sibling relationships, the correlations were significantly stronger than in the vertical parent-child relationships, except for the relationship of the younger children with their father and sibling.

To examine whether family members who are more agreeable within specific relationships perceive more support in these relationships, the correlations between a family member's relationship effect for perceived support and his or her dyadic partner's relationship effect for Agreeableness were computed. Most correlations were significant (Table 2), indicating that individuals who perceive a specific family member as more agreeable are perceived as more supportive by this partner than individuals who perceive a specific family member as less agreeable. Only two correlations were nonsignificant: the correlation between mothers' perceived Agreeableness from younger children and younger children's perceived support from mothers and the correlation between older adolescents' perceived Agreeableness from mothers and mothers' perceived support from older adolescents. Again, zscore comparisons showed that correlations were higher for horizontal marital and sibling relationships than for vertical parent-child relationships, except for the difference in correlations between the Agreeableness that mothers perceive from father and children and the support that fathers and children perceive from mother.

In addition, the family effect for perceived support significantly correlated with the family effect for Agreeableness $(r=.86, p<.01)$, suggesting that in families where

Table 1

Correlations between family members' Agreeableness and perceived support across relationships

\begin{tabular}{|c|c|c|c|c|}
\hline & \multicolumn{2}{|c|}{ Intrapersonal correlations } & \multicolumn{2}{|c|}{ Interpersonal correlations } \\
\hline & $\begin{array}{c}\text { Actor effect } \\
\text { Agreeableness- } \\
\text { support }\end{array}$ & $\begin{array}{l}\text { Partner effect } \\
\text { Agreeableness- } \\
\text { support }\end{array}$ & $\begin{array}{c}\text { Actor effect } \\
\text { Agreeableness- } \\
\text { partner effect } \\
\text { support }\end{array}$ & $\begin{array}{c}\text { Actor effect } \\
\text { support- } \\
\text { partner effect } \\
\text { Agreeableness }\end{array}$ \\
\hline Father & $.65^{\star \star}$ & $.61^{\star \star}$ & -.07 & .05 \\
\hline Mother & $.73^{\star \star}$ & .09 & .11 & .06 \\
\hline Older adolescent & $.63^{\star \star}$ & $.62^{\star}$ & -.02 & -.14 \\
\hline Younger adolescent & $.51^{\star \star}$ & $.88^{\star \star}$ & -.16 & .06 \\
\hline
\end{tabular}

${ }^{\star} p<.05 ;{ }^{\star \star} p<.01$. 
Table 2

Correlations between Agreeableness and perceived support within relationships

Relationship effect Agreeableness - support

\begin{tabular}{|c|c|c|c|}
\hline \multicolumn{2}{|l|}{ Intrapersonal } & \multicolumn{2}{|l|}{ Interpersonal } \\
\hline Father $\rightarrow$ older child - father $\rightarrow$ older child & $.26^{\star \star}$ & Father $\rightarrow$ older child - older child $\rightarrow$ father & $.27^{\star \star}$ \\
\hline Mother $\rightarrow$ father - mother $\rightarrow$ father & $.57^{\star \star}$ & Mother $\rightarrow$ father - father $\rightarrow$ mother & $.19^{\star}$ \\
\hline Mother $\rightarrow$ older child - mother $\rightarrow$ older child & $.30^{\star \star}$ & Mother $\rightarrow$ older child - older child $\rightarrow$ mother & $.24^{\star \star}$ \\
\hline Mother $\rightarrow$ younger child - mother $\rightarrow$ younger child & $.20^{\star \star}$ & Mother $\rightarrow$ younger child - younger child $\rightarrow$ mother & .16 \\
\hline Older child $\rightarrow$ mother - older child $\rightarrow$ mother & $.42^{\star \star}$ & Older child $\rightarrow$ mother - mother $\rightarrow$ older child & .09 \\
\hline Younger child $\rightarrow$ older child - younger child $\rightarrow$ older child & $.70^{\star \star}$ & Younger child $\rightarrow$ older child - older child $\rightarrow$ younger child & $.38^{\star *}$ \\
\hline Younger child $\rightarrow$ father - younger child $\rightarrow$ father & $.89^{\star \star}$ & Younger child $\rightarrow$ father - father $\rightarrow$ younger child & $.24^{\star \star}$ \\
\hline Younger child $\rightarrow$ mother - younger child $\rightarrow$ mother & .15 & Younger child $\rightarrow$ mother - mother $\rightarrow$ younger child & $.12^{\star}$ \\
\hline
\end{tabular}

Horizontal correlations are printed in italics.

${ }^{\star} p<.05 ;{ }^{\star \star} p<.01$.

individuals perceive more support the individuals are also more agreeable. This relation generalises to the family as a group.

\section{Discussion}

Taken together, the results of the current study confirmed the hypothesis that family members who are more agreeable are also more supportive, both across relationships and within relationships. Individuals who perceive all family members as supportive perceive all family members as agreeable, individuals who are perceived by all family members as supportive are perceived by all family members as agreeable, and individuals who perceive specific family members as supportive perceive these specific family members as agreeable. In contrast, family members who are more agreeable perceive more support only within specific relationships. Individuals who perceive all family members as more agreeable are not perceived as more supportive by all family members, but individuals who perceive specific family members as more agreeable are perceived as more supportive by these specific family members. Thus intrapersonal links occur across and within relationships but interpersonal links occur only within specific relationships.

The results for intrapersonal links between support and Agreeableness support the idea of different levels of relational schemas. Whereas the links between perceptions of a family member's Agreeableness and supportiveness across relationships may reflect general relational schemas, the relationshipspecific links may reflect relationship-specific schemas (Fletcher, 1993; Koerner \& Fitzpatrick, 2002). The finding that individuals who perceive their family members as more agreeable perceive more support from these family members across relationships points to the influence of individuals' cognitive representations of others in interpreting their behaviour (Baldwin, 1992). It seems that a person's generalised view of others has a strong relation to that person's 'sense of support" (I. G. Sarason et al., 1990). However, the link between perceived Agreeableness and perceived support across relationships is not totally due to the effect of an individual's working model of others. The strong significant correlations between the partner effects of Agreeableness and support revealed that someone's Agreeableness as perceived and agreed upon by all family members was also related to the support all family members agree to perceive from that person. In addition, intrapersonal links occurred partly within relationships: Individuals who perceive specific family members as more agreeable also perceive these specific members as more supportive. This shows that personal characteristics are to some extent context- or relationship-specific. Individuals are differentially agreeable in specific dyadic family relationships, which affects support perceptions in these relationships. Thus, relations between Agreeableness and support are partly affected by generalised relational schemes and partly by relationship-specific schemes.

A salient result of the study was that, for interpersonal relations between Agreeableness and support, being generally agreeable to all family members does not elicit more support from all family members. Individuals who are perceived as more agreeable across relationships do not perceive more support across relationships. Instead, only when a specific family member perceives an individual as uniquely agreeable within that specific relationship, will the individual perceive more support from this member. Conversely, only when someone is perceived as uniquely unfriendly by a family member, will less support be perceived from that member. Again, this points to the significance of the specific match between two family members and reciprocity processes in dyadic relationships. The interpersonal behaviour of the dyadic partners in family members is characterised by mutuality of exchanges. Although personality characteristics are often assumed to affect individuals across contexts, our results suggest that dyadic partners have to perceive the friendly behaviour as uniquely directed towards them. Only then will they reciprocate with support.

Mothers seem to have an exceptional position in the family with regard to links between Agreeableness and support. In contrast to all other family members, mothers who are generally perceived as more agreeable are not generally perceived as more supportive by their family members. In addition, in the relationship with their husbands, a mother's 
perception of her husband's Agreeableness did not appear to be related to the support that he perceived from her. Being generally and unconditionally supportive seems to be inherent to the role of mother and wife, and does not depend on the personal characteristics of mothers. It may be that mothers indeed try to provide support to the members of their nuclear family independent of the personal characteristics of these members. Alternatively, family members may perceive mothers as supportive to some extent, independent of the support mothers actually provide, because the cultural stereotype of mothers is one of a supportive caregiving person. This result may be related to the low partner variance in mothers' support in these four-person families: There are no differences across families in the support that all family members perceive from the mother (Branje et al., 2002).

An additional finding was that relationship-specific processes between Agreeableness and support were more consistent and stronger in horizontal marital and sibling relationships than in vertical parent-child relationships. There were only a few exceptions to this finding: in the horizontal relationship between mothers' perceived Agreeableness from fathers and fathers perceived support from mothers, interpersonal correlation were low (as discussed above), and in the vertical adolescent-father relationship intrapersonal relationship-specific correlations for adolescents' perceptions of fathers were relatively high. These results implicate the idea that parents' specific perception of their children as agreeable is only weakly related to their level of specific perceived support from these children. Put differently, parents who perceive their children as more agreeable do not tend to perceive more support from them than parents who perceive their children as less agreeable, and the reverse may hold as well, namely that independent of the support parents perceive from their children, they may perceive their children as more or less agreeable. The finding that the relationship-specific Agreeableness and support are more strongly related in horizontal relationships, except for the Agreeableness that mothers perceive from fathers and the support that fathers perceive from mothers, suggests that reciprocity between Agreeableness and support is especially important in the sibling relationship and in fathers' relationships towards mothers. Adolescents acting in a specifically nice way towards their sibling will get more support from that sibling, and mothers acting in a specifically nice way towards their spouse will get more support from him. However, mothers are supportive toward their spouse and children regardless of how agreeable their spouse and children are.

These differences between horizontal and vertical relationships suggest that family members make relational attributions regarding the support and Agreeableness they perceive in horizontal dyads and mutually affect each other mainly in these horizontal relationships. Consistent with these findings, earlier studies revealed that relationship-specific effects and dyadic reciprocity are stronger in horizontal family relationships than in vertical ones for perceived support (Branje et al., 2000). An explanation may be that in horizontal relationships, dyad members match each other's level of exchanges to preserve equity in the relationship (Rusbult \& Van Lange, 2003). In some marital or sibling relationships, the partners are nice to each other and support each other; in other such relationships, hostility is common and the partners are less likely to support each other. Compatible with this explanation is the finding that perceived mutuality in marital relationships is related to higher adjustment (Genero, Miller, Surrey, \& Baldwin, 1992; Noller \& White, 1990), and that perceiving support in marital partners is only related to more positive and less negative mood if support is part of an exchange in which both partners perceive and give support to each other (Gleason, Iida, Bolger, \& Shrout, 2003). Relationship-specific processes are clearly a crucial aspect of horizontal relationships. Less relationshipspecific processes were found for vertical parent-child interactions. In these relationships, family members' roles may affect their behaviour more strongly. For example, the parents' role is to provide care, security, and support for their children regardless of the characteristics of these children. In sum, our results suggest that a sense of mutual obligation and equal exchanges are more necessary to maintain horizontal relationships than vertical relationships. These findings emphasise the importance of distinguishing between different types of relationships.

One may argue that the concepts of Agreeableness and support are comparable and might both have been an assessment of being helpful. There are, though, several arguments against this suggestion. For instance, perceived support is assessed in terms of concrete behaviour whereas personality is assessed in terms of general traits. Also, the relational support instrument not only assesses emotional support and helpful behaviour, but also openness of communication and agreement on motives and goals. These aspects of relational support may have relations to personality factors other than Agreeableness. Furthermore, of the Big Five factors, an individual's Conscientiousness is found to be most strongly related to supportive behaviour when people are in a hurry (Reynolds \& Karraker, 2003), and the partner's Conscientiousness is found to be the strongest predictor of support perceived from an unacquainted partner (Lakey, Ross, Butler, \& Bentley, 1996b).

A limitation of the current study is that it addressed family relationships during adolescence only. Future research needs to examine whether support-Agreeableness links not only differ for horizontal versus vertical relationships, but also for different sex constellations, different roles within the family, or different provisions of support. Additionally, further research will need to address whether these findings can be generalised to other types of relationships in other contexts.

To conclude, our study showed that it is important to examine relations between personal characteristics such as Agreeableness and relationship qualities such as perceived support across different dyadic relationships and from the perspective of different individuals. Only then can links that are generalised across relationships be distinguished from links within specific relationships. Whereas intrapersonal relations between support and Agreeableness are partly generalised across relationships and partly relationship-specific, interpersonal relations between support and Agreeableness are only relationship-specific. Furthermore, links between Agreeableness and support within specific relationships were stronger in horizontal relationships.

\section{References}

Asendorpf, J. B., \& Van Aken, M. A. G. (2003). Personality-relationship transaction in adolescence: Core versus surface personality characteristics. Fournal of Personality, 71, 629-666.

Baldwin, M. W. (1992). Relational schemas and the processing of social information. Psychological Bulletin, 112, 461-484. 
Branje, S. J. T., Van Aken, M. A. G., \& Van Lieshout, C. F. M. (2002). Relational support in families with adolescents. Fournal of Family Psychology, 16, 351-362.

Branje, S. J. T., Van Aken, M. A. G., Van Lieshout, C. F. M., \& Mathijssen, J. J. J. P. (2003). Personality judgments in adolescents' families: The perceiver, the target, their relationship, and the family. Fournal of Personality, 71, 49-81.

Branje, S. J. T., Van Lieshout, C. F. M., \& Van Aken, M. A. G (2004). Relations between Big Five personality characteristics and perceived support in adolescents' families. Fournal of Personality and Social Psychology, 86, 615-628.

Browne, M. W., \& Cudeck, R. (1989). Single sample cross-validation indices for covariance structures. Multivariate Behavioral Research, 24, 445-455.

Bugental, D. B., \& Goodnow, J. J. (1998). Socialization processes. In W. Damon (Series Ed.) \& N. Eisenberg (Volume Ed.), Handbook of child psychology. Vol. 3: Social, emotional, and personality development (5th ed., pp. 389-465). New York: Wiley.

Cook, W. L. (1993). Interdependence and the interpersonal sense of control: An analysis of family relationships. Fournal of Personality and Social Psychology, 64, 587-601.

Cook, W. L. (1994). A structural equation model of dyadic relationships within the family system. Fournal of Consulting and Clinical Psychology, 62, 500-509.

Cook, W. L. (2000). Understanding attachment security in family context. fournal of Personality and Social Psychology, 78, 285-294.

Finch, J. F., \& Graziano, W. G. (2001). Predicting depression from temperament, personality, and patterns of social relations. Fournal of Personality, 69, 27-55.

Finkenauer, C., Engels, R. C. M. E., Branje, S. J. T., \& Meeus, W. (2004). Not all relationships are created equal: Disclosure and relationship satisfaction in the family context. Fournal of Marriage and Family, 66, 195-209.

Fletcher, G. J. O. (1993). Cognition in close relationships. New Zealand fournal of Psychology, 22, 69-81.

Genero, N. P., Miller, J. B., Surrey, J., \& Baldwin, L. M. (1992). Measuring perceived mutuality in close relationships: Validation of the Mutual Psychological Development Questionnaire. Fournal of Family Psychology, 6, 36-48.

Gerris, J. R. M., Houtmans, M. J. M., Kwaaitaal-Roosen, E. M. G., Schipper, J. C., Vermulst, A. A., \& Janssens, J. M. A. M. (1998). Parents, adolescents, and young adults in Dutch families: A longitudinal study. Nijmegen, The Netherlands: Institute of Family Studies, University of Nijmegen.

Gleason, M. E. J., Iida, M., Bolger, N., \& Shrout, P. E. (2003). Daily supportive equity in close relationships. Personality and Social Psychology Bulletin, 29, 1036-1045.

Goldberg, L. R. (1992). The development of markers of the Big-Five factor structure. Psychological Assessment, 4, 26-42.

Hartup, W. W. (1989). Social relationships and their developmental significance. American Psychologist, 44, 120-126.

Haselager, G. J. T., \& Van Aken, M. A. G. (1999). Codebook of the research project Family and Personality: Vol. 1. First measurement wave. Nijmegen, The Netherlands: University of Nijmegen, Faculty of Social Science.

Jensen-Campbell, L. A., \& Graziano, W. G. (2001). Agreeableness as a moderator of interpersonal conflict. Fournal of Personality, 69, 323-362.

Jöreskog, K. G., \& Sörbom, D. (1996). LISREL 8: User's reference guide. Chicago, IL: Scientific Software International.

Kashy, D. A., \& Kenny, D. A. (1990). Analysis of family research designs: A model of interdependence. Communication Research, 17, 462-482.

Kenny, D. A. (1994). Interpersonal perception: A social relations analysis. New York: Guilford Press.

Kenny, D. A., \& La Voie, L. (1984). The Social Relations Model. In L. Berkowitz (Ed.), Advances in experimental social psychology, Vol. 18 (pp. 141182). San Diego, CA: Academic Press.
Koerner, A. F., \& Fitzpatrick, M. A. (2002). Toward a theory of family communication. Communication Theory, 12, 70-91.

Lakey, B., Adams, K., Neely, L., Rhodes, G., Lutz, C. J., \& Sielky, K. (2002). Perceived support and low emotional distress: The role of enacted support, dyad similarity and provider personality. Personality and Social Psychology Bulletin, 28, 1546-1555.

Lakey, B., \& Cassady, P. B. (1990). Cognitive processes in perceived social support. Fournal of Personality and Social Psychology, 59, 337-343.

Lakey, B., \& Cohen, S. (2000). Social support theory and measurement. In S. Cohen, L. G. Underwood, \& B. H. Gottlieb (Eds.), Social support measurement and intervention: A guide for health and social scientists (pp. 29-52). London: Oxford University Press.

Lakey, B., McCabe, K. M., Fisicaro, S. A., \& Drew, J. B. (1996a). Environmental and personal determinants of support perceptions: Three generalizability studies. Fournal of Personality and Social Psychology, 70, 1270 1280 .

Lakey, B., Ross, L. T., Butler, C., \& Bentley, K. (1996b). Making social support judgments: The role of similarity and conscientiousness. Fournal of Social and Clinical Psychology, 15, 283-304.

Laursen, B., \& Bukowski, W. M. (1997). A developmental guide to the organisation of close relationships. International fournal of Behavioral Development, 21, 747-770.

Lollis, S., \& Kuczynski, L. (1997). Beyond one hand clapping: Seeing bidirectionality in parent-child relations. Fournal of Social and Personal Relationships, 14, 441-461.

Lutz, C. J., \& Lakey, B. (2001). How people make support judgments: Individual differences in the traits used to infer supportiveness in others. Fournal of Personality and Social Psychology, 81, 1070-1079.

Maccoby, E. E. (1992). The role of parents in the socialization of children: An historical overview. Developmental Psychology, 28, 1006-1017.

Noller, P., \& White, A. (1990). The validity of the Communication Patterns Questionnaire. Psychological Assessment, 2, 478-482.

Pierce, T., Baldwin, M. W., \& Lydon, J. E. (1997). A relational scheme approach to social support. In G. R. Pierce, B. Lakey, I. W. Sarason, \& B. R. Sarason (Eds.), Sourcebook of social support and personality. The Plenum series in social/clinical psychology (pp. 107-140). New York: Plenum Press.

Reynolds, B., \& Karraker, K. (2003). A Big Five model of disposition and situation interaction: Why a "helpful" person may not always behave helpfully. New Ideas in Psychology, 21, 1-13.

Rusbult, C. E., \& Van Lange, P. A. M. (2003). Interdependence, interaction and relationships. Annual Review of Psychology, 54, 351-375.

Russell, A., Pettit, G. S., \& Mize, J. (1998). Horizontal qualities in parent-child relationships: Parallels with and possible consequences for children's peer relationships. Developmental Review, 18, 313-352.

Sarason, B. R., Pierce, G. R., \& Sarason, I. G. (1990). Social support: The sense of acceptance and the role of relationships. In B. R. Sarason, I. G. Sarason, \& G. R. Pierce (Eds.), Social support: An interactional view (pp. 97-128). New York: John Wiley.

Sarason, I. G., Pierce, G. R., \& Sarason, B. R. (1990). Social support and interactional processes: A triadic hypothesis. Fournal of Social and Personal Relationships, 7, 495-506.

Sarason, I. G., Sarason, B. R., \& Shearin, E. N. (1986). Social support as an individual difference variable: Its stability, origins, and relational aspects. fournal of Personality and Social Psychology, 50, 845-855.

Scholte, R. H. J., Van Lieshout, C. F. M., \& Van Aken, M. A. G. (2001). Perceived relational support in adolescence: Dimensions, configurations, and adolescent adjustment. Fournal of Research in Adolescence, 11, 71-94. 